\title{
To Harmonise or Not to Harmonise? The Case of Cross-national Biotechnology Governance in Southern Africa
}

\author{
Julius Mugwagwa'
}

\begin{abstract}
This paper is based on a study which investigated both existing and new regulatory responses to food emergencies and bigger challenges presented by modern gene-based biotechnologies. In particular, this paper looks at the challenge of cross-national cooperation in regulation of these technologies in southern Africa. One response to this challenge which has dominated policy agendas in the region for a long time, and with more prominence after the 2002-2003 food emergency, is that of harmonisation of national biosafety regulatory systems. Harmonisation is touted by its promoters as one way in which countries can buttress weaker national and sub-national regulatory capacities, and develop synergies that will place them in a strong position to deal with the dynamic challenges presented by modern biotechnologies. The desire for cross-national cooperation in biotechnology management was investigated from the broader perspective of policy convergence, with harmonization being but one of the mechanisms towards the policy convergence. A number of factors facilitating or inhibiting policy convergence were identified, including but not limited to cultural, institutional, socio-economic and policy community attributes. The paper concludes that an understanding of these factors is crucial if grounded empirical and theoretical proposals on cross-national policy convergence are to be advanced.
\end{abstract}

Keywords: African Union; SADC; NEPAD; biotechnology; biosafety; harmonisation; policy convergence.

'Department of Design, Development, Environment and Materials, Chambers Building, Ground Floor, The Open University, MK7 6AA, Milton Keynes, United Kingdom; Phone: 00441908332 5I7; Fax: 0044 1908 654 825; Email: j.t.mugwagwa@open.ac.uk 


\section{Introduction}

'Instead of thinking about policy as a routine engagement between certain public officials and a settled retinue of established interests, we are now forced to consider how a single system is constructed from semi-independent institutions and actors linked by resource agreements, joint agreements, joint projects and cross-border engagements ... it is really composed of pads of unequal size, each contributing to a characteristic policy 'footprint' (Considine, 2005:127).

\section{Background}

Southern African countries have found themselves in the throes of food emergencies in the past, for example, in 1991, when a severe drought combined with inadequate human, infrastructural and organizational capacity in domestic markets to severely constrain food supplies leaving millions of people on the verge of starvation (Omamo and von Grebmer, 2005:2). The food emergency of 2002-2003 had, by and large, the same cast of issues drought, infrastructural, organizational and policy factors - BUT with an additional challenge - that the thousands of tonnes of food available to help cover the shortages were suspected to contain unspecified amounts of genetically modified (GM) maize. Uncertainties around food and environmental safety and regulatory preparedness meant that some countries were unwilling to accept the food aid, with some governments going on record to 'choose starvation', rather than let their people consume 'poisonous food'2 (e.g. Panos Report No.49, 2005:30). The challenges that this dilemma presented ranged from the grandiose and perennial task of putting in place regulatory and institutional arrangements to the mundane logistical hurdles of "how to load grain into rail cars and trucks with minimal escape, how to cover the loaded cars and trucks and how long to allow the trucks to sit in given positions' (Omamo and von Grebmer, 2005:2). The scenario created tension at various levels: within countries, between countries, with food relief agencies and donors, among others, as affected countries in the region endeavoured to make the best decision, both individually and collectively, under pressure from the food emergency and the uncertainty posed by the suspected GM-food (Moola and Munnik, 2007). At the policy level, the dilemma is attributed with having raised the political temperature around regulation of biotechnology ${ }^{3}$, both within countries and at the cross-national level. At the national level for example, a number of measures had to put in place to guide decision-making, with some countries, e.g. Zimbabwe and Malawi, deciding to distribute only milled grain and Zambia refusing the grain outright (Mafa, 2004; Moola and Munnik, 2007, Clark et al, 2005). At the regional level, Southern African Development Community $^{4}$ (SADC) agriculture ministers cited the lack of a harmonized regional position on GMOs as creating serious operational problems in the movement of food and non-food items, and recommended the formation of an advisory committee on biotechnology and biosafety ${ }^{5}$ to develop guidelines on this issue and t-he broader issues around biotechnology (SADC 2003). Meanwhile, SADC Heads of State in their August 2003 Summit in Maputo, Mozambique, set a deadline of December 2004 for all countries of the SADC region to put in place national biosafety systems ${ }^{6}$ (SADC, 2004).

\footnotetext{
${ }^{2}$ For a detailed account of the 2002/2003 food aid challenge in southern Africa, see Clark et al (2005) and Herrick (2008).

${ }^{3}$ The science of biotechnology has as many terms as it does skeptics.A number of synonyms are in use for the for the process or science of biotechnology including:"genetic modification" and "genetic engineering" or the term "agbiotech." The food products of biotechnology can be referred to as GMOs, transgenic foods, GM foods, genetically engineered (GE) foods, or biotech foods. These terms have been used interchangeably in this paper for the sake of variation but all refer to the same process and product.

${ }^{4}$ The 15 countries making up SADC are:Angola, Botswana, DR Congo, Lesotho, Madagascar, Malawi, Mauritius, Mozambique, Namibia, Seychelles, South Africa, Swaziland, Tanzania, Zambia and Zimbabwe. They are all at significantly different levels with respect to development and utilization of biotechnology, and the measures for governing it. South Africa is the leading country, not only in the SADC region, but the whole of Africa, having already commercialized production of GM maize and cotton, and also having a legally-binding biosafety system since 1997. Zimbabwe (1998), Mauritius (2002), Malawi (2004) and Zambia (2006) are the other countries that have biosafety legislation, while the rest of the countries have draft legislation still at various levels of progress towards enactment (see further details in Mugwagwa, 2008:30). ${ }^{5}$ Further details in section on SADC.

${ }^{6}$ In this paper, a national biosafety framework or system is defined as "a combination of policy, legal, administrative and technical instruments that are developed to ensure an adequate level of protection in the field of the safe transfer, handling and use of living modified organisms resulting from modern biotechnology that may have adverse effects on the conservation and sustainable use of biological diversity, taking also into account risks to human health" (ref; UNEP-GEF, 2006).
}

ISSN: 07I8-2724. (http://www.jotmi.org) 
While all this was happening, the key issues and realities for biosafety are that while there is a significant level of agreement on the potential risks associated with GM technologies; for example environmental risks from gene flow to non-cultivated plants, agronomic risks from resistance problems in the GM crops and in weeds, coexistence challenges between fields of farmers using GM-crops and those not using them; among others - there is still considerable disagreement within and across countries regarding the level of these risks and the scientific possibilities for adequately assessing and addressing them (Birner and Linacre, 2008). Add to these the disagreements on the so-called non-science issues, such as labelling of food and feed derived from GM crops, and socio-economic issues around the technologies, one then begins to sympathise with the existence of a continuum of regulatory systems, ranging from the 'stringent' EU system on one end to the 'permissive' US system on the other end (Levidow et al, 1996, Paarlberg, 2000). As noted by Arcuri (200I), a 'regulatory divide' has emerged, championed by 'technocrats' on one hand, who believe in a rational application of the science to identify and manage the risks; and a 'deliberative' philosophy on the other hand, which embeds scientific knowledge within policy and societal debates (cf. Birner and Linacre, 2008). These divides also exist in the SADC region, and how they oppose or cultivate fertile grounds for cooperation are among the key areas of focus for this paper. One agenda which has dominated policy discussions in the region for a long time, and unsurprisingly with more prominence after the food emergency, is that of harmonisation of national regulatory systems. Harmonisation is touted by its promoters as one way in which countries can strengthen weaker national and sub-national regulatory capacities, and develop synergies that will place them in a strong position to deal with the dynamic challenges presented by the technologies and products thereof. A number of organizations have entered the policy arena in southern Africa, to champion the harmonisation agenda directly, or to tackle other levels within the policy/regulation development spectrum. The study on which this paper is based focused on the roles of three supranational organizations (SNOs), the African Union (AU), the New Partnership for Africa's Development (NEPAD) and the Southern African Development Community (SADC) in bringing about this cross-national cooperation. This paper, while making reference to how the three organisations and related others are aligning themselves to help countries in this agenda, focuses primarily on the contextual realities facilitating or constraining harmonisation specifically or policy convergence processes broadly. Meanwhile, to avoid a 'mechanism-dependent bias' (c.f. Bennett, 1991), this desire for cross-national cooperation was investigated from the broader perspective of policy convergence, with harmonisation being but one of the mechanisms towards the envisaged collective response to the collective challenge.

\section{Some key processes towards cross-national cooperation in biosafety}

The African Union set up a group of experts in June 1999 to draft a comprehensive framework of biosafety regulations that would serve as a model law to protect Africa's biodiversity, environment and the health of its people. This initiative resulted in the African Model Law (AML) on Safety in Biotechnology which was finalized in May 2001. In July 2003 Decision EX/CL/Dec.20-74 (III) ${ }^{7}$ of the AU Executive Council endorsed the Africa-wide Capacity Building Programme on Biosafety in which adoption of the AML was encouraged for creation of 'a harmonised Africawide space and system in biosafety.... In November 2006, the Human Resources, Science and Technology (HRST) Directorate of the AU Commission proposed an African Strategy on Biosafety ${ }^{8}$ in which, among other issues harmonisation through Regional Economic Communities (RECs) and use of the AML was encouraged. A December 2006 Conference of AU Ministers of Agriculture ${ }^{9}$ declared an 'African Position on GMOs in Agriculture', emphasizing the precautionary approach and establishment of a 'mechanism to facilitate harmonisation of regulatory systems' e.g. through encouraging and facilitating dialogue between RECs (SADC being one of these). Since 2005, the HRST Directorate has implemented an Africa-wide Biosafety Capacity Building Project with funding from the German Government.

\footnotetext{
${ }^{7} \mathrm{AU}$ EX/CL/Dec.20-74 (III)

${ }^{8} \mathrm{AU}$ (2006b). African Strategy on Biosafety

${ }^{9} \mathrm{AU}$ Dec 2006a - An African Position on GMOs in Agriculture
} 
The Southern African Development Community (SADC) is recognised as one of the first of Africa's regional economic communities (RECs) to develop guidelines on GMOs and Biotechnology, and this happened in response to the food aid crisis which followed the 2002-2003 drought in the region ${ }^{10}$. In 2003, the SADC Secretariat, through its Food, Agriculture and Natural Resources (FANR) Unit set up the SADC Advisory Committee on Biotechnology and Biosafety (SACBB), to draft guidelines/ recommendations on handling of food aid, policy and regulations (including harmonisation), capacity-building and public participation in biotechnology and biosafety. The Committee was reconstituted in 2007 after a three year period of low activity to develop and propose institutional arrangements for a 'SADC Framework on the Safe Handling and Transboundary Movement of GMOs'". The proposed framework recommends establishment of a SADC Biosafety Focal Point, to which Member States will communicate national decisions on GMOs. Among other provisions, countries will be responsible for monitoring their obligations under the Framework; while cooperation in research and development on biotechnology and biosafety is 'encouraged' and the SADC Secretariat is tasked to 'coordinate and mobilise the required resources'. Disputes among countries will be referred to the SADC Tribunal (Article 16 of the SADC Treaty). Meanwhile, in 2007, through the SADC Ministerial Council on Science and Technology ${ }^{12}$, the region developed a Protocol ${ }^{13}$ on Science, Technology and Innovation (STI) in which harmonisation of biotechnology policies and regulations is one of the targets. An STI Unit is proposed, to be housed in the SADC Secretariat.

In 2005, NEPAD, in partnership with the AU set up a high level African Panel on Biotechnology (APB) to analyze the African biotechnology terrain and make recommendations on how best to use the technology for Africa's development, including developing an African strategy on biotechnology and biosafety. The APB was mandated to propose and promote the adoption of a regional strategy that reflects Africa's common values, articulates shared needs and focuses on common opportunities. The Panel produced a report, Freedom to Innovate: Biotechnology in Africa's Development (Juma and Serageldin, 2007) which was disseminated to key partners and regional economic communities. Meanwhile, NEPAD, through its Office of Science and Technology (OST) $)^{14}$ and the African Ministerial Council on Science and Technology also implements an African Biosciences Initiative (ABI) and the African Consolidated Plan of Action (CPA) for Science and Technology through Centres of Excellence in Eastern, Western, Southern and Northern Africa as part of a 'coevolution approach' to technology and policy development.

\section{Policy convergence}

Policy convergence is premised on growth in similarity of policies, policy scope, institutional and implementation arrangements, among others (Bennett, 199I; Knill, 2005). Policy convergence thus constitutes the results of a process in which countries are assumed to have moved from varying positions towards some common point. While knowledge that national policies have converged is useful, it remains silent about the motivations behind the convergence, and the mechanisms through which the convergence has been achieved. This paper presents and discusses research findings based on the different conceptions of similarity, how it occurs and how to measure it. An open-ended strategy, grounded in participants' accounts, document reviews and observations was used.

This study drew inspiration from other studies and published works on cross-national policy convergence, and on multi-actor interactions broadly [for example Busch and Jorgens (2005); Dolowitz and Marsh (2005); Seeliger (1996); Holzinger, et al, (2006); Franzese and Mosher (2002) and Gauthier (2002); among others]. The cross-cutting, multi-level and multi-actor nature of biotechnology and biosafety issues, combined with the cross-national level at which the issue was being investigated, meant that a number of conceptual and theoretical perspectives would come to the fore in trying to understand this issue. The study was about how countries are attempting to exploit technological opportunities and manage risk at a multi-country level, and about how they try to be innovative within the different pressures they face, both as individual countries and as a collective entity. The

\footnotetext{
${ }^{10}$ e.g. Clark et al, 2005

"Ref - Draft SADC Framework on the Safe Handling and Transboundary Movement of GMOs

${ }^{12}$ This is part of the African Ministerial Council on Science and Technology (AMCOST), which is coordinated by the NEPAD.

${ }^{13}$ Ref: SADC - Draft 2 - Protocol on Science, Technology and Innovation

${ }^{14}$ www.nepadst.org
}

ISSN: 07I 8-2724. (http://www.jotmi.org) 
aim was understand how the differences on many fronts within the countries were serving as a rallying point for a transnational governance arrangement.

The main focus of most studies on policy convergence is on policy output, i.e. the policies adopted by the countries, as opposed to the policy outcome. Policy outcomes are usually affected by many intervening variables, which make it difficult if not impossible to relate the outcomes directly to the causal mechanisms of convergence. Therefore it would not be surprising to find convergence at the level of output, but divergence at the outcomes level. With respect to research hypotheses, many authors are in agreement that formulating hypotheses on the level of convergence is a difficult task because identifying the level or 'point' of a policy to then come up with a convergence point is not always easy (Holzinger and Knill, 2005a). Convergence implies a decrease in variation among policies over time, and the unit of measurement is thus the decrease in standard deviation from one point in time to another. A change in the regulatory level means a shift either downwards or upwards of the mean between the two measurement times (Botcheva and Martin, 200I). Therefore to assess convergence, and a shift in the regulations, a reference point is needed. In this paper, the commencement time reference point was 2002, at which point the cross-national cooperation agenda was only beginning to gather momentum, and the regulatory systems in the countries were characterized by extensive diversity. The study covered a 6-year period up to 2007. In this period, because of the intensity of discussion of biosafety issues at national, regional and international levels, measurable activity towards convergence was expected.

In addition to setting reference frames for the measurement of convergence, researchers are in general agreement that measurement of convergence is removed from the coincidence domain if observation of the phenomenon is made in a large sample of countries (Leifferink and Jordan, 2002). There is a possibility for changes to run parallel in two countries with different national sources of change. This was the motivation for looking at the 15country SADC region, as opposed to comparing only a few countries in the same region.

\section{An agenda embedded in images of risk}

As presented earlier, cross-national policy convergence is defined as the increase in policy similarity between countries over time (e.g. Bennett, 1991). This section of the paper looks at some theoretical perspectives which bring an understanding of the different argumentations around the issue, and more importantly how these impact on the convergence agenda. From the onset, it emerged that the framing of issues in the discussions around crossnational convergence of biosafety systems mirrored the same hopes and fears observed in the debates around the science of biotechnology itself. There was a prominent cluster of issues around the newness of the technology, and the expectations that it had built across societies. Negative impacts of some of the 'failed' promises of the technology (for example the lofty promises of increasing agricultural productivity and reducing hunger and poverty) were said to await its regulation. Past failures of some cross-national cooperation programmes, including even other unrelated science and technology programmes, were all lumped together as impediments to the convergence agenda. On the other hand, pro-convergence respondents highlighted success scored by the technology (e.g. GM cotton production by smallholder farmers in South Africa, disease diagnosis and therapeutic remedies, among others) and by the three organizations as pointers to potential success of the convergence agenda.

To help illuminate how different motivations are shaping or responding to the convergence agenda, a number of theoretical perspectives are deployed, including the sociology of expectations in science and technology risk colonization theories explained below.

\section{Sociology of expectations}

Societal views on new technological developments are shaped by events and experiences that societies have gone through in the past (Borup et al, 2006). These embedded images create favorable expectations or negative perceptions about development, resulting in significant impacts on the institutional and policy processes to receive and accommodate new developments. The close link between framings around a technology and those around its regulation make it worthwhile to focus on how expectations around science and technology shape 
people's understandings and framings of policy change. Expectations are defined as wishful enactments of the desired future (Borup et al, 2006). They are both positive and negative and the way an intervention is framed defines the expectations around it. Expectations and visions are not constant; they vary in space and time, and they span as well as bring together different groups within a society (Considine, 2005: 23). These groups and the linkages that they form may vary, say from country to country, making it difficult to predict how given groups of stakeholders in different jurisdictions would perceive certain technologies. However, with the rise of the knowledge society, knowledge has become a central driving element and there is also an increase in the amount of communication across national, institutional and epistemic borders (Borup et al, 2006; Evans and Davies, 1999). This is expected not only to result in an increase in shared visions and meanings across frontiers, but across disciplinary boundaries and knowledge networks as well (Stone, 2000). Professionals in different disciplines have been seen to reach beyond the borders of their own specific fields of expertise to establish relationships with wider and more heterogeneous networks of potential collaborators. For this study, these dynamics were seen as factors with a potential to bring together motivations in the cross-national convergence agenda.

The existence of a unified policy community, geared towards the envisaged output, is among the factors known to facilitate cross-national policy convergence (Gertler, 200I; Drezner, 200I). Members of this community all recognize the problems caused by existing fragmentation, and are all prepared to set aside conceptual differences for the greater good of their polity through a consensual transnational governance framework. In the SADC, one challenge to the existence of such a unified policy community was that in the countries themselves, there was limited organizational, sectoral or national consensus on the issue. Expecting these differences to suddenly disappear at the regional level was labeled by one respondent as 'a heroic dream': the tensions and contentions would likely be elevated. The fact that the policy communities and policy networks in countries differed also affected the knowledge exchange that should happen between these stakeholders across countries, prior to the convergence process (cf. Levy, 1997). The absence of uniformity results in discordant communication across countries, a situation that can potentially hamper an already fragile policy agenda.

\section{Risk colonization}

Continuing with the look at the organisation of the technology and policy debates around risk, another key theoretical perspective around the hopes and fears for convergence is the risk colonization theory. This theory is used here to build on to some of the issues illuminated by the sociology of expectations; but looking specifically at the distinction between societal risk and institutional risks. Risk colonization theory contends that 'risk has become an increasingly key organising concept' or has 'colonised' debates about regulatory regimes and extended governance systems, so that we can also talk broadly of a 'risk society', where we have become concerned with 'risk management of everything' (Power, 2004). According to Rothstein et al, (2006), institutional risk refers to 'threats to regulatory organisations, and/ or the legitimacy of rules and methods of regulation'. As will be discussed later, one key issue mentioned by almost all the respondents throughout this study, was the importance of the process of obtaining convergence, as opposed to the actual convergence itself. Stakeholders were keen on owning and understanding the processes, and seeing that they were addressing their needs, and those of the region. There were thus pressures towards transparency, and accountability of the processes. By stepping onto the podium to champion the convergence agenda, the three SNOs (NEPAD, the AU and SADC) and programmes initiated by other organisations, were exposing themselves to scrutiny from the stakeholders both inside and outside the region. In their own accounts of issues around the convergence process, some operatives from these organisations also acknowledged this double focus on their systems and the technology itself, and the net result it had of raising stakeholder expectations on the issue. Some respondents also felt that there was too much fragility at the regional policy-making level, including the continuous shift by governments to new and more pressing policy agendas. Champions of this agenda thus faced increased risk of losing their reputation as a result of failed deliveries, e.g. from lack of resources, and lack of general stakeholder as well as political commitment to see through the processes. This paper seeks to bring further insight on these issues and an informed understanding on whether convergence is a positive, zero or negative sum game. 


\section{Methodology}

This paper emanates from a three-year case study which sought to understand existing and new impetus for crossnational regulatory systems for modern biotechnology sparked in southern Africa by the 2002-2003 food aid crisis. The study examined the roles of the three SNOs, $A U, N E P A D$ and SADC, who, together with other regional and international bodies have independently or jointly initiated processes to assist the 15-country SADC region towards cross-national similarity or convergence of biosafety systems. Those who participated ${ }^{15}$ in the study included scientists, policy makers and representatives of NGOs, the three SNOs and other policy actors from the region and beyond. The study was guided by the three factor conceptualisation of Per Olof Busch and Helge Jorgens (2005), which proposes cooperative harmonisation of domestic practices, interdependent but uncoordinated diffusion and coercive imposition of policy practices as three distinct international mechanisms causing policy change and policy convergence ${ }^{16}$. A number of researchers have demonstrated that causes of domestic policy change do not come from national sources only, but they also quickly indicate that these causes are also not limited to isolated responses to global pressures either (Holzinger and Knill, 2005; Rose, 2000). Thus the theoretical perspectives, data gathering and analysis approaches for this study adopted an interdisciplinary and multi-method approach in navigating the complex technological, regulatory and socio-political settings. Data was collected primarily using questionnaires ${ }^{17}$, semistructured interviews and document reviews throughout the study period, and in-situ observation of processes and organisational interactions during a three-month internship at NEPAD in the middle of 2007 and during various meetings and workshops ${ }^{18}$ attended during the study period between 2006 and 2008. Analysis was done mainly using thematic analysis ${ }^{19}$ (Boyatzis, 1998). The following sections present and discuss the various technological, policy and wider contextual realities in southern Africa, and how they are shaping and/or responding to the convergence/harmonisation agenda.

\footnotetext{
${ }^{15}$ Fifty six (56) responses obtained out of a total of 68 individual participants contacted at one stage or another throughout the data collection period between March 2006 and August 2007. Other statistics: 20 respondents participated in the pilot study; and 25 of the 68 (36.8\%) completed the second questionnaire, II interacted with the project throughout, while 47 of the 56 were interacted with both formally and informally, i.e., beyond use of the questionnaires.

${ }^{16}$ These three classes of mechanisms are distinct with regard to their mode of operation, the principal motivations of policy makers to adopt policies and the leeway they grant national policy makers to influence the content and independently decide on the adoption of a policy or regulatory system (Busch and Jorgens, 2005). Examining everyday constructions of the convergence issues, and observation of policy processes, the three classes of mechanisms were seen to capture the range of options and forces facing the countries of the study region in their quest for a transnational governance framework for biosafety, and the aim was to understand how the SNOs were innovating around the context through use of these mechanisms. Therefore, the typology of Busch and Jorgens was chosen for its ability to serve both cognitive purposes and systematic analysis of policy convergence using a combination of mechanisms. Most of the research on convergence is currently limited to analysis of single mechanisms (Heichel et al, 2005, Bennett I99I and Drezner, 200I). See Mugwagwa (2008) and Busch and Jorgens (2005) for further details on this typology.

${ }_{17}$ Two sets of questionnaires were used as the main research instruments for this study. The questionnaire or checklist used at the beginning of the study consisted of broad, open-ended questions which were aimed at identifying and mapping the key issues around the research topic. Design of this questionnaire was based on my prior experience in the geographical and policy area targeted by the research, and guided by literature surveys within the area of biotechnology regulation broadly and cross-national policy convergence specifically. The second questionnaire raised questions and traced perspectives pursuant to issues emerging from the first round of the data gathering process and review of relevant literature.

${ }^{18}$ Notably the Ist Congress of African Scientists and Policy Makers held in Alexandria, Egypt, Nov 2007

19 Thematic analysis can be defined as the interpretation of qualitative data through organizing it into codes, categories and themes (Boyatzis, 1998: 18). Themes, which are patterns found in the data, may be generated inductively from the raw data, or deductively from theory and prior research. Thematic analysis is a systematic way of working with information that increases the accuracy and sensitivity in understanding and interpreting observations. According to Boyatzis (1998: I5), 'thematic analysis can assist in communication between positivistic science and interpretive science, between testers of ideas and developers of ideas, between builders of theories and social constructionists'. This makes it an ideal approach for translating methods and results into forms accessible to others from different fields, orientations or traditions of inquiry, and for this research, this could not have been more appropriate given one of the underlying desires which was to bridge research and policy. In addition, biosafety is a cross-cutting undertaking, and the need for a robust analytic framework was therefore imperative. This approach was also useful in all stages of the research; from the early stages of the inquiry where it helped organize thoughts and emerging issues, to the interpretation stages, where it served as a guide for the emerging research story.
}

ISSN: 07I8-2724. (http://www.jotmi.org) 


\section{Reasons for desiring convergence}

The reasons why convergence was desirable were invariably highlighted in the same vein with the reasons why general or broader cross-national cooperation or collaboration was desirable (cf. ECA, 2006). There was an underlying belief that having similar policy and regulatory systems would improve cooperation and collaboration across various sectors of the national economies (cf. Mugabe, 200I; SADC Review, 200I). In other words, barring different interpretation of similar policies, chances for policy and regulatory conflicts would be greatly minimized if countries had similar policies. With respect to biotechnology, this was largely seen as being even more fundamental because of the high attendant costs for setting up and running sustainable technological and policy systems (Ushewokunze-Obatolu, 2005; Birner and Linacre, 2008). Therefore, while the cooperation agenda had been a key issue in the region for decades, biotechnology was seen as bringing a functional impetus to the agenda (cf. Radaelli, 2000). Pro-convergence stakeholders, in particular laboratory scientists and regulatory officers, pointed to some costs which the region had had to bear already because of the fragmented approach to the development and regulation of biotechnology. Examples of these costs include the 2002/03 food aid debacle (Clark et al, 2005: 75) which brought divisions and loss of credibility to the scientific community. These tensions resulted in scientists spending most of their time debating biotechnology at the expense of their research duties. The credibility ${ }^{20}$ of the science community was highly shaken, especially because of the differences that arose among scientists in some of the countries, notably Zambia (Panos Report, 2005; Omamo and von Grebmer, 2005: 7) and all this was largely attributed to the policy vacuum ${ }^{21}$ (Ushewokunze-Obatolu, 2005). The vacuum resulted in many operatives in some of the smaller countries being called upon to make decisions beyond their capabilities (cf. Haas, 1992), stretching and compromising their already fragile positions.

In the backdrop of the challenges and opportunities brought by the technology, countries had sought to collaborate at different levels in order to bring synergies that would benefit all of them. As highlighted earlier, countries were at different levels of technology utilization and policy development and this was seen as having the potential to give positive impetus to coordinated development and management of the technology through experience-sharing among the countries. In a world in which developmental disparities can be a major driver for economic and technological cooperation (ECA, 2006; Newmark, 2002; also Wilson, 2007 on why knowledge differentials should be a resource not a problem), stakeholders in the region also saw geographical contiguity among the regional countries as a major benefit in the quest for cooperation. Requirements for cooperation driven by this geographical contiguity, where it not only became easier for the cooperation to happen, but the spillover effects of what happened within the confines of another country also made it essential for countries to work together. National borders were porous, and national cultures spanned these borders and shared policy arrangements were seen as one way of adequately preparing national institutions to deal with this reality. This view was in agreement with Article 26 of the Cartagena Protocol on Biosafety which requires countries to take into account socio-economic considerations such as impact of living modified organisms on their neighbours before they made their decisions. Converged policy and regulatory systems would thus not only help countries deal with their internal challenges, but would also help them build regulatory and administrative capacity to deal with external challenges and opportunities and meet their obligations at the national, regional and international levels.

The technology also came with many competitive forces, especially from a market point of view where multinational corporations have a strong push (cf. Botcheva and Martin, 200I). Fragmented efforts by countries of the region would not put them in a good position to deal with the forces, argued some respondents from science and technology research organisations. Cooperation and synergies would help to build the necessary scale economies to position the region not only as a strong force to resist technology and product dumping and other malpractices, but also as an attractive region for favourable technologies and products. Even in the face of countries enjoying different bilateral and multilateral partnerships, many argued that those separate partnerships would benefit from the backdrop of a united and coherent regional policy platform.

Most of the national economies in the region were too small and too constrained in terms of technical and regulatory capacities to afford to develop, let alone support the various structures needed for effective management of modern technologies (Ushewokunze-Obatolu, 2005). Cooperation with other countries would enable responsibility-sharing in some of the aspects. One aspect mentioned consistently is risk assessment and management, where, because of the geographical and environmental similarities among the countries, it would be largely feasible for assessments or measures made in one country within the region to be applicable to other countries. In principle, capabilities for various technological and regulatory aspects around biotechnology could spread across clusters of countries and be made available for the benefit of the entire region. Having similar regulatory systems was expected to facilitate this spread. This mode of operation has been tried successfully in some areas (for example in the customs and excise under the Southern African Customs Union (SACU) where some goods do not need individual country approvals), and pro-convergence respondents called for the same concept to be tried for biotechnology management. A number of benefits would accrue to the countries and the region as a result of this

\footnotetext{
${ }^{20}$ E.g. meaning power to elicit belief or confidence among different stakeholder groups.

${ }^{21}$ Lack of policy direction or leadership
} 
cooperation, experience-sharing and streamlining of procedures, including reducing procedure turnaround time and overall cutting of regulatory costs. From a risk management perspective, the bigger scale would enable the region to have a bigger voice when calling for enforcement of regulations meant to preserve the environment, e.g. as provided for under the Cartagena Protocol on Biosafety, as one proponent from one of the SNOs argued:

"For all intents and purposes, convergence of biosafety systems is about getting the best from the systems for the countries, for the region and for our technological and economic partners. It is not about giving the region unfair advantage, because at the end of the day, the region needs those same partners in the broader walk towards socio-economic development, and the benefits will accrue to everyone in the end. People talk about resistance to change, and this is a typical case where extra-regional forces are resisting change being motivated by the region, and our challenge is thus on how to make them see our vision in the same way as us" [Res2I ${ }^{22}(S)$, Oct 2007].

A further dimension to the 'discomfort' among extra-regional forces was the strong feeling among some proponents of convergence that the region's commitment to working together, including the convergence agenda, could be derailed by some powerful external forces who were sceptical about the region's intentions and ability to sustain the commitment. Examples were given of supposedly negative reporting of issues before, during and after the AU summit of January 2007 regarding Africa's preparedness to take science, technology and innovation issues seriously. It was felt that such negative perspectives, especially from 'respected' opinion shapers served as a hindrance to positive progress. Stakeholders indicated, almost pleaded, that while they welcomed and expected criticism, it was also prudent at times for the efforts being made to 'at least receive some appreciation' as a way of encouraging the continent. It was clear from this encounter that practitioners were keen to defend their programmes, with some even claiming that they spent a better part of their working time justifying and defending their programmes, further dissipating institutional resources. Why this could not be done by dedicated PR offices could not be ascertained, but the end result was that negative feelings were brought to the policy terrain, and the tension created could be felt for several months after the encounter. However, as Rothstein et al (2006) indicate, 'blame-avoidance behaviour at the expense of delivering core business is a well-documented organisational rationality'.

The other main reason why countries desired convergence was the envisaged cooperation in dealing with challenges being faced in developing and implementing national systems. The convergence agenda was thus related to how a country felt weak or vulnerable on its own, triggering the desire to collaborate with others. The areas of weakness, needing strengthening through cooperation, e.g. technical and legal capacity, varied from country to country, and they depended also on a country's aspirations and targets with respect to biotechnology and biosafety. Variations also occurred within different policy communities in a given country. There were also different policy communities in each country, and multiple pressures on the convergence discourse from individual, institutional, sectoral, national, regional and international perspectives.

From the above, it was clear that the compelling factors for convergence varied from shared histories and cultural values, the need for synergistic and strategic cooperation in technology development, to the need to have a unified front as a regional economic market. Admittedly, some factors were stronger than others. As one policy maker from one of the SNOs noted;

"Biosafety largely brings countries together or pits them against each other in the realms of trade and environmental safety. What then comes to the fore is how the two opposing forces balance each other out, bearing in mind that some countries pay more attention to one or the other set of issues" [Pmk223 (S), Aug, 2007]

One observation that was made was the inconsistency and the varied emphasis around the issues that were brought to the agenda table. Some fora would emphasise the shared histories agenda, while others would dwell on the culture dimension, yet others would focus on the economic and technological benefits that could accrue to the region as a result of shared policy positions. Still it was not uncommon for all these issues to be debated in one forum, the sticking point always being how to bring them all together given the existing disciplinary boundaries, and in some cases the lack of representation in these fora from government agencies mandated to deal with those issues. The challenges encompassed both the framing and the operational dimensions, and this raised the barriers for the convergence agenda. Also, as mentioned earlier, the desire for convergence of the regulatory systems followed closely the debates in the technology itself, and the biggest forces around the issue related to the operational context for the regulations and the technology. The catch 22 for the technology and the regulations was that each was mentioned as being well placed to create opportunities for the other, and how this would unfold in reality remained to be seen.

\section{Fears around convergence}

The buoyancy about convergence was however not shared among all respondents, with some seeing it as another policy fad that would just disappear with time. It was interesting to observe that those who were skeptical were mainly those policy makers and regulators who had been in the policy arena for a long time, who therefore probably knew what was feasible and what was not, but who may also be just fatigued, and believing that nothing will ever change. The newer players were quick to point fingers at the long-stayers, with one of them, a senior official in the ministry of science and technology in one of the countries saying;

${ }^{22}$ Coded respondent:A researcher from one of the SNOs
${ }^{23} \mathrm{~A}$ policy maker/senior official from one of the SNOs 
"The biggest fear I have on this issue is that there are too many people who are tired, and who will never see things happening beyond what they deem feasible. These people have established themselves to such an extent that they cannotseparatethemselvesfrom theissue, and any challenge to the status quo is perceived as a direct challenge to them as individuals and their wisdom. We have to start with such people if things are to change" [Pmk424 (R), July 2007].

It was very clear from the statement above and from the other realities observed in the region that the hopes and fears around the technology, its regulation and the convergence agenda had to look beyond the technology itself. The wider regulatory and institutional context had a major impact on what was feasible, to what extent and the sustainability of the interventions. For example, as revealed above, the fact that part of the policy community also consisted of members who had championed the processes that were being targeted by the changes represented a source of potential internal resistance (and impetus) that could not be overlooked (cf. Considine, 2005:55), and also revealed the complexity of knowledge flows within policy communities.

\section{National and sub-national interests}

The drive towards cross-national convergence was seen to be a balancing game between national interests, including sovereignty and right to auto-interpretation of international law, and regional aspirations, as much it was a balancing game for the various sub-national interests. Stakeholders argued that the process and the output that would best balance these multiple and fluctuating interests would then more than likely lead to an attainment of convergence. However, given the multiplicity and the internal as well as external location of the forces behind these interests, the attainment of convergence was admitted to be challenging, 'and might not be worth the attention and resources it was getting', according to one respondent from an NGO. This was also the main reason, as the same respondent pointed out, why the galvanizing factors were always changing, in reality or in framing only; reflecting an elusive search for a set of factors which were appropriately framed and shared by the region to enable a sustained regional focus towards convergence. Hilgartner and Bosk (1988) in their 'arenas model' refer to the importance of promoters of policy issues in sustaining it within the policy space in which there are other issues competing for attention. Many questions therefore arise regarding the way learning takes place and how it can be sustained within such a dynamic policy space. From a functionalistic point of view, NEPAD, the AU and SADC and other programmes were attempting to influence the playing field so that more predictable learning and boundary crossing could take place (cf. Stone 2000).

It also emerged that there were unfulfilled technological and regulatory expectations at sub-national and national levels, and stakeholders were keen to have these addressed before moving to the regional level (e.g. the limited successes of the RBFP25, the AU Model Law on Safety in Biotechnology; among others). It was observed that in this case the fears were directed more at the context, as opposed to the various organizations championing the convergence agenda. In other instances, the fears centered on the delivery capacity of the organizations championing the process. In the final analysis this duality represents the practical challenges of reconciling the various tensions around the issue and the pressures that champions of the policy processes face for stepping into the policy arena.

\section{International goals}

The dominant presence of international regulatory and technological targets was said to be compelling the regional grouping and the member states to rush towards convergence, when they would be better off achieving incremental sub-national, national or regional goals. Considerable pressure was being put on countries as they did not want to be seen as failing to comply with standards that other countries were adhering to, and sometimes this affected firm underpinning of processes in national goals and imperatives ${ }^{26}$. The envisaged convergence was seen

\footnotetext{
${ }^{24}$ Policy maker/senior official from one of the SADC countries

${ }^{25}$ Regional Biosafety Focal Point - a Dutch funded regional programme on biosafety implemented in 14 Eastern and Southern African countries between 1993 and 1997 (Chetsanga and Chigogora, 200I).

${ }^{26}$ This was the opinion of most respondents who have taken part in international negotiations, notably the International Treaty on Plant Genetic Resources (ITPGRC) and the Cartagena Protocol on Biosafety
} 
J. Technol. Manag. Innov. 20II,Volume 6, Issue 3

as having the potential of diverting countries' focus and resources from their own processes towards the regional desires. It was therefore argued that given the slow pace at which conclusion of international policy processes took place; the desired convergence would also slow down the rate at which national processes took place. Generally, the international goals were not only slow in being set, but they also fluctuated a lot as a result of the oftenconflicting national, corporate and other forces around them. This put the goal-setting and decision-making process beyond the influence of the weak countries in the region and other parts of the developing world (cf. ECA, 2006). In response, countries have however tried to form international negotiation coalitions (for example during the negotiations of the Biosafety Protocol) to try and counter some of these challenges. The desire for regional convergence of biosafety systems was seen by some sections of policy makers as one way of trying to institutionalize the positive lessons from the negotiations around the Biosafety Protocol. On the other hand, this was viewed as an external motivator, and given the lack of unanimity within the Protocol negotiation process, some opponents saw this as 'inheriting a weakness which will come back to haunt the regional convergence process'. They further argued that the push for convergence should not be modeled around rich versus poor, or as pitting environment and trade interests against each other, as what happened in the Protocol negotiations, because the region could ill-afford these dichotomies. The need for consensus on why convergence was desirable was highlighted, although some were quick to point out that this (consensus attainment) would mark another complex and protracted policy struggle which would unnecessarily divert the region's focus. It was underscored that the consensus-building and the move towards the convergence should be attempted at the same time. It was also highlighted that trying to evade the different sectoral tensions (e.g. trade $v$ environment etc) would only serve to create fallacies that would result in improper policy outputs. On the whole, it was abundantly evident that the interaction between the domestic and external forces for and against convergence seemed to have a bigger influence than first realised, especially when one took into view their link with the bigger macro-setting of the countries and the region.

\section{Turning a blind eye to the costs}

While the motivators for convergence were highlighted, an analysis of the costs of divergence seemed to be only an implied converse of the positives. Some respondents argued that as long as this un-quantified cost remained 'not so huge a deterrent', then the necessary motivation could remain weak. One respondent from a scientific research institution in Namibia was very emphatic:

'Sometimes it's not about what stands to be gained, but what stands to be lost ... I think it is true that African countries have tended to be stronger in staking their claim in situations where there is much to be lost; and in this case, we need to know what it is we stand to lose by continuing to develop and implement our systems independently. Also, it's not as if there is no cooperation already. It is there as and when necessary, and maybe that's all we require" [Res22 (R), Mar 2007].

The same respondent indicated that countries of the region seemed to have a lot of inertia as far as 'going for gains' was concerned. Maybe it had to do with the pressures, competition and other variables at play where there was room for a gain, because the bigger and stronger countries and other players would also be clamouring to occupy those vantage points. There was divided opinion in the SADC on whether to go for gain (harness the technology) or defend what was there (e.g., environmental protection). This was another level of the major emerging narratives for biosafety in particular and convergence in general in southern Africa; one school looking at 'what do we stand to gain' and another school looking at 'what do we stand to lose' (linked closely to level of use of the technology and development of regulatory systems). All this had implications on institutional arrangements as well as human, technological and other arrangements that needed to be put in place to make convergence of systems at the cross-national level feasible. South Africa for example was looking at being a bio-economy, and saw Sub-Saharan Africa as a market for products, while the rest of the countries did not have the same confidence and preparedness to have these visions. The other countries are at different positions in the continuum from the protectionist intentions to the technology exploitation objectives. Not surprisingly, South Africa was said to look more outside the region for technological and policylessons. This clash between the protective and forward-looking approaches was a challenge for the convergence agenda, 
starting from whether it was feasible or not, to the nature of the achievable convergence once the initial hurdles had been cleared. Yet it was also appreciated by most of the respondents that it would not be possible for there to be permanent and uncontested agreement on convergence, given the realities transcending the technology and the SADC region. It was therefore up to the stakeholders to find the best way of packaging their similarities in a way that galvanised rather than kept them apart.

\section{Resource diversion}

There were also some fears based on resource diversion, for example, that once a regional technology management structure was in place, donors would prefer to put resources there at the expense of national programmes. This in many ways showed that stakeholders had no confidence in their own governments honouring their national obligations and making sure the national processes were kept going, feeding into the regional level arrangements. However, these fears of resource diversion and competition were real, and they exposed the fallacy of shared ideals around regional cooperation. Some respondents were quick to point out that already there were tensions between national programmes and some NEPAD initiatives. For example, some donors, especially the 'big donors' preferred to channel their assistance through NEPAD for quicker spread of their visibility, among other reasons, than doing so through national programmes. Such donors therefore favoured crossnational convergence of regulatory systems. Meanwhile, apart from the attraction of financial resources, personnel, for example consultants, would also be more attracted to regional programmes than to national programmes, usually because of higher remuneration. There was the fear therefore that solving the regional level challenges could lead to escalation of the national problems, which were supposed to be the ingredients for viable regional programmes. In the final analysis, the truth of the matter was that any different policy and institutional arrangement brought with it a competition dimension because of resource and capacity constraints, and this diminished the enthusiasm towards it, as individuals and organizational actors alike felt threatened, eliciting some kind of negative feedback scenario (cf. Considine, 2005:43).

\section{Dampening innovation}

Other fears were around how adoption of regional systems could curtail policy innovation in countries. Some respondents from government institutions argued that as much as there were both internal and external pressures necessitating urgency in coming up with functional systems, countries needed to go through the experience curve, in order to be able to own the policy instruments, as opposed to adopting and implementing lessons from elsewhere. This issue locks into many domains, for example sovereignty, and capacity building, where countries emphasized linking issues of biosafety at both national and regional levels to the broader national requirements, and ensuring that capacities for related policy responses were built. However, it was argued that sovereignty alone did not bring the needed incentive in development of programmes and processes, and there was need to balance the 'freedom to innovate' with avoiding 'reinventing the wheel'. Others argued that countries of the region ought to appreciate that they had come a long way already through the experience curve, and maybe it was high time other measures, such as regional convergence, were put in place to stimulate further innovation.

\section{Threats to established relationships}

As mentioned previously, tensions existed between 'cooperation with partners' from outside the region (on the technology) and 'strength in numbers' from a regional standpoint. Some countries felt they benefited more from their partnerships with technology-rich trading partners outside the region, and they felt that the region only brought strength, in so far as managing technology risks was concerned. This was by no means an unimportant component of the agenda, but, according to some respondents who chose to portray themselves as realistic ${ }^{27}$, for developing the technology, some of the countries in the region had nothing to offer, and even the risk management dimension in some cases needed to be looked at beyond the strength-in-numbers perspective.

This was a significant tension area and one where coexistence was needed, because it was not conceivable

${ }^{27}$ Mainly laboratory scientists from one of the leading scientific and industrial research centres in the region

ISSN: 07I8-2724. (http://www.jotmi.org)

Journal of Technology Management \& Innovation (c) Universidad Alberto Hurtado, Facultad de Economía y Negocios 
that existing relationships would have to end, while at the same time, having these and the new regional arrangements for biosafety would in some cases create incompatibility problems. Pragmatic policy innovation and looking beyond narrow institutional and national interests may be needed to ensure a win-win scenario from this tension. The example of the UK-EU-US relations is a typical case in point for this tension, with the UK fully aware of the potential gains and losses of further integration into the EU given the long relationship with the US, which predates even the earliest roots of the $\mathrm{EU}^{28}$. However, some international crises have arisen of late, in which many have questioned the prudence of the continued close alliance with the US, when the EU seems to have come of age. This was the same scenario that some SADC countries faced, and the challenge was how to balance the positives from both intra and extraregional alliances, especially in cases where they seemed to compromise each other. This seemed to throw weight to the notion of case-by-case cooperation arrangements, although it was a fact that cross-national relations were built over time, based on trust, and this might not happen as quickly as it should in times of crises if a case-by-case approach was adopted. The bigger and more complex issues around convergence were thus more daunting than a simple cursory glance could reveal.

One fallacy that countries would need to deal with, according to some respondents, was that of a permanent convergence, and one in which countries would be agreeing all the time. The differences amongst the countries in the pre-convergence era should be ample evidence that countries would always have differences. There was need to define the minimum differences that would not threaten the convergence or in whose presence the convergence would still subsist. This was a missing link, and as one respondent, a biosafety expert from the region now based in the UK pointed out:

"Proponents of convergence should not fool themselves that there will come a time when countries will look at themselves as having been unreasonable at some stage. Countries will always see the justification for whatever views they hold (or have held), and it is how these differences are addressed which matters. If one country is expected to make a fool of itself, then for that simple reason, they may resist even the best of ideas" [Res 19 (OR), Mar 2007]

This again lent support to the earlier assertion by most stakeholders that it was the process of obtaining convergence, as opposed to the convergence output, which was more important in determining the feasibility of convergence. This was also in line with the convergence hypothesis, where different systems came together, with each one bringing its good attributes to the common agenda.

\section{Conclusions}

This paper has described the contending stakeholder views on cross-national convergence or harmonisation of biosafety systems in southern Africa, laying bare the daunting task of either creating a predictable environment for cross-national learning; or ensuring effective learning even in this dynamic environment. Key among the many realities is the lack of a sustained, shared and adequately framed convergence agenda, as a result of the fluctuations within the region. This raised many questions at the higher level regarding how and why countries come together to cooperate on an issue. With respect to regimes, for example, some scholars argue that governments create or join regimes in order to make their commitments credible (Hasenclever et al, 2000). From the empirical results presented in this paper, there is some truth that some countries saw a regional approach to biotechnology management as a way of bolstering the credibility of the systems they were developing and employing in their domestic settings. Some countries were also advocating for convergence as a way of demonstrating their commitment to regional integration (through functional cooperation) and demonstrating their commitment to having the technology effectively regulated. There were also desires to promote investment in the technology, or meeting obligations or expectations of other partners with which the countries had relationships. These issues of credibility and demonstrating commitment seemed to work both ways; in that they could also be used by some countries to push against convergence as a way of showing their allegiance to the bigger forces that might be dictating to them certain positions, e.g. donors and development partners who were against biotechnology.

\footnotetext{
${ }^{28}$ Robert Whelan, Sept 2007 Article on UK, EU and US relations: Foreign Policy Fears: the 'special relationship' versus strength in numbers
} 
This paper also showed that a government's commitment to other governments through pushing for convergence may not only be at variance with their commitment to other external partners, but to domestic actors as well. Convergence is a balancing game where the government has to deal with many issues at vertical and horizontal levels within the broader socio-economic setting, at both national and regional levels. The question that remains, however, is if convergence is about demonstrating commitment, why would governments choose to demonstrate commitment through convergence? Why not demonstrate it through other means of cooperation. This was an argument presented by some neutrals who chose to call themselves realists ... pointing to the inherent fragility of the converged position, given the different and fluctuating allegiances that the governments had to deal with. They also said the overall policy decisions in this technology were not entirely in 'the hands' of the national governments in the region, making the whole convergence agenda at the worst, 'an exercise in futility'. It was also clear that policy convergence efforts were not separate policy endeavours, but were part of wider policy processes, especially within discussions around science and technology, agriculture, environment and trade. The wider processes therefore shaped these convergence efforts, as much as the convergence efforts shaped the processes. In addition, there was recognition that in facilitating convergence, the SNOs and other organisations were dependent on other actors and thus could not be viewed as isolated change agents. There was thus a significant role for agency in these processes, particularly around choices in selection of policy ideas, which was likely to result in bounded rationality in the imitation, copying or modification of policy innovations by decision makers.

Reference to external forces came hand-in-hand with perceptions of 'coercion', or limited choice among policy actors. On the other hand, a focus on voluntary mechanisms has been confirmed by other studies to direct analytical attention to the internal attributes and salient features of policy arenas, such as similar political ideologies, policy styles, culture, language, and institutional arrangements. This study also confirmed these trends, while also establishing that the various convergence mechanisms may not necessarily act uniformly in different polities, and that there were different sources of the policy lessons, ranging from internal to international sources. In the final analysis, this paper concludes that in the case of cross- national cooperation in biosafety in southern Africa, this close look at contextual realities is important if grounded understandings of the feasibility of the cross-national convergence agenda are to emerge.

\section{Acknowledgements}

This paper is based on the author's $\mathrm{PhD}$ research into the process towards cross-national convergence of biosafety systems in southern Africa, looking specifically at the roles of three supranational organizations, AU, NEPAD and SADC. Sincere gratitude to the Open University and ESRC Innogen Centre for funding the work; to Prof Joanna Chataway and Dr Peter Robbins at the Open University, and Dr James Smith at Edinburgh University for guidance and mentorship, and to the Leverhulme Trust for funding further work on this study through an early career fellowship.

\section{References}

BENNETT, C. J. (199I). What is policy convergence and what causes it? British Journal of Political Science, vol. 2I, no. 4, pp. $215-223$.

BIRNER, R. and Linacre, N. (2008). Regional biotechnology regulations: Design options and implications for good governance, International Food Policy Research Institute Discussion Paper 00753.

BORUP, M., Brown, N., Konrad, K. and Van Lente, $H$. (2006). The sociology of expectations in science and technology, Technology Analysis and Strategic Management, vol., 18, nos. 3-4, pp. $285-298$.

BOTCHEVA L. and Martin L. L. (200I). Institutional effects on state behaviour: convergence and divergence, International Studies Quarterly, vol. 45, pp. I - 26.

BUSCH, P-O. and Jorgens, H. (2005). The international sources of policy convergence: explaining the spread of environmental policy innovations. Journal of European Public Policy, vol. 12, no. 5, pp. 860 - 884.

CLARK, N., Mugabe, J. and Smith J. (2005).Governing agricultural biotechnology in Africa: Building public confidence and capacity for policy-making. African Centre for Technology Studies Press, Nairobi, Kenya. 
CONSIDINE, M. (2005). Making public policy. Polity Press, Cambridge (UK) and Malden (USA).

DIMAGGIO, P. J. and Powell, W. W. (1983). The iron cage revisited: Institutional isomorphism and collective rationality in organisational fields. American Sociological Review, vol. 48, no. 2, pp. 147 - 160.

DREZNER, D.W. (200I). Globalisation and policy convergence. The International Studies Review, vol. 3, no. I, pp. $53-78$.

ECONOMIC COMMISSION FOR AFRICA (2006). Assessing regional integration in Africa II: Rationalising Regional Economic Communities. United Nations Economic Commission for Africa and African Union.

EVANS, M. and Davies, J. (1999). Understanding Policy Transfer: A Multi-level, Multi-disciplinary perspective, Public Administration, vol. 77, no 2, pp. 36I - 385.

GERTLER, M.S. (200I). Best practice? Geography, learning and the institutional limits to strong convergence. Journal of Economic Geography, vol. I, pp. 5 - 26.

HAAS, P. M. (1992). Introduction: epistemic communities and international policy coordination, Interrnational Organisation, vol. 46, no. I, pp. I - 35.

HASENCLEVER, A., Mayer, P. and Rittberger, V. (2000). Integrating theories of international regimes. Review of International Studies, vol. 26, pp. 3 - 33.

HERRICK, C. (2008). The Southern African Famine and Genetically Modified Food Aid: The Ramifications for the United States and European Union's Trade War, Review of Radical Political Economics, Volume 40, No. I, Winter 2008, 50-66

HILGARTNER, S. and Bosk, C. L. (1988). The rise and fall of social problems: A public arenas model, American Journal of Sociology, vol. 94, no. I, pp. $53-78$.

LENSCHOW, A., Liefferink, D. and Veenman, S. (2005). When the birds sing. A framework for analysing domestic factors behind policy convergence. Journal of European Public Policy, vol.12, no. 5, pp. 797 - 816.
LEVY, D. A. (1997). Regulating digital broadcasting in Europe: The limits of policy convergence, Western Union Politics, vol. 20, no. 4, pp. $24-32$.

MAFA, A. (2004). Managing biotechnology in Zimbabwe; paper presented at a national stakeholders' workshop to present the Draft National Biotechnology Policy and National Biotechnology Management Authority Bill, Sheraton Hotel, Harare, December 9 - 10.

MILLER, G. and Dingwall, R. (eds.) (1997) Context and method in qualitative research, SAGE Publications, London, Thousand Oaks, New Delhi.

MOOLA, S. and Munnik, V. (2007). GMOs in Africa: food and agriculture, Status report 2007, African Centre for Biosafety.

MUGABE, J. (200I). Biotechnology and sustainable development in Africa: Towards regional consensus and common strategy, Paper prepared for the African Ministerial Conference on Science and Technology.

NEWMARK, A. J. (2002). An integrated approach to policy transfer and diffusion. The Review of Policy Research, Summer 2002, vol.19, no. 2, pp.15I - 178.

OMAMO, S.W. and von Grebmer, K. (eds). Biotechnology, Agriculture and Food Security in Southern Africa, Washington DC and Harare: IFPRI and FANRPAN, 2005.

PANOS REPORT (2005). The GM debate - Who decides? An analysis of decision-making about genetically modified crops in developing countries, Report No. 49, Panos, London.

RADAELLI, C. M. (2000). Policy transfer in the European Union: institutional isomorphism as a source of legitimacy. Governance: An International Journal of Policy and Administration, vol. 13, no.l, pp. 25 - 43.

ROSE, R. (1991). What is lesson drawing? Journal of Public Policy, vol.II, pp. 3 - 30 .

ROTHSTEIN, H., Huber, M. and Gaskell, G. (2006). A theory of risk colonisation: the spiralling regulatory logics of societal and institutional risks, Economy and Society, vol. 35, no.I, pp. 91 - II2. 
SADC Review 200I. Poverty reduction: A top priority in SADC. www.sadcreview.com/sadc (accessed 10 March 2006).

STONE, D. (2000). Learning Lessons, Policy Transfer and the International Diffusion of Policy Ideas, Centre for the Study of Globalisation and Regionalisation, Working Paper No 69/0I, The University of Warwick.

USHEWOKUNZE-OBATOLU, U. (2005). Biosafety policy: in Biotechnology, Agriculture and Food Security in Southern Africa; eds. Omamo, SW and von Grebmer, K (2005). IFPRI and FANRPAN, Washington and Harare.

WILSON, G. (2007). Knowledge, innovation and reinventing technical assistance for development, Progress in Development Studies, 7, 3, pp. 183-99. 
J. Technol. Manag. Innov. 20II,Volume 6, Issue 3 